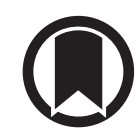

CrossMark

\title{
Asthma paradoxes: time for a new approach across the spectrum of asthma severity
}

To the Editor:

I read with interest the editorial from BEASLEY et al. [1]; in part, because we are proud to declare ourselves the first short-acting $\beta_{2}$-agonist (SABA) free asthma department.

I see the necessity of including one outstanding paradox from the Global Initiative for Asthma (GINA) [2]. SABA is the only single pharmacological agent that crosses horizontally all the treatment steps; and the reference is an anonymous review [3]. SABA is used in asthma based on customs and traditions, rather than by evidence A (i.e. top level scientific support). This review [3] was classified by GINA as evidence A (refer to GINA report [2], p. 46, line 4).

The first paradox is that SABA overreliance link behaviour developed at the expense of inhaled corticosteroid (ICS) treatment [4]. That means that poor adherence to ICS and overreliance on SABA are both faces of the same coin. Not only should SABA not be used as monotherapy, but also not as a reliever with ICS therapy [5].

The second paradox is that there is strong evidence that maintenance ICS with concomitant SABA reliever therapy results in superior efficacy [6]. However, regular SABA therapy showed more severe exacerbations than placebo or salmeterol despite simultaneous ICS treatment [7].

SABA could also be replaced in the emergency room setting, as well as during hospitalisation. ICS was included in a guideline for acute asthma exacerbation due to its non-genomic bronchodilator action [8]. Formoterol had similar performance when compared with SABA in an acute setting [9].

In our Pulmonary Section, we only use SABA for other obstructive lung diseases different from asthma. Further, we are planning to replace SABA for spirometry.

Before incorporating long-acting muscarinic antagonist (LAMA) as a third controller at step 4, replacement of SABA with ICS/SABA or ICS/fast-onset long-acting $\beta_{2}$-agonist (LABA) demonstrated a greater reduction in asthma exacerbation than the addition of tiotropium (21\% reduction [10] versus $28 \%$ reduction with budesonide/formoterol [11]).

Regarding potential limitations: a high ICS dose is always preferred instead of systemic corticosteroids. High doses of fast-onset LABA have adverse effects that are similar to high doses of SABA. Strong consideration should be given to ICS/fast-onset $\beta$-agonist reliever therapy replacing the current advice for SABA reliever therapy across the range of asthma severity. By the way, it is better defined as anti-inflammatory reliever strategy.

Luis J. Nannini

Pulmonary Section, Hospital E Perón de G Baigorria, Universidad Nacional de Rosario, Santa Fe, Argentina.

Correspondence: Luis J. Nannini, Pulmonary Section, Hospital E Perón de G Baigorria, Ruta 11 y E Perón, G. Baigorria, Santa Fe 2152, Argentina E-mail: linannini@hotmail.com

Received: Dec 102018 | Accepted: Jan 172019

Conflict of interest: L.J. Nannini reports personal fees from Sanofi Genzyme and AstraZeneca, outside the submitted work.

@ERSpublications

Short-acting $\boldsymbol{\beta}_{2}$-agonist free asthma management and anti-inflammatory rescue therapy http://ow.ly/ us0L30nHmUE

Cite this article as: Nannini LJ, Pulmonary Section, Hospital E Perón de G Baigorria, Universidad Nacional de Rosario, Santa Fe, Argentina. Asthma paradoxes: time for a new approach across the spectrum of asthma severity. Eur Respir J 2019; 53: 1802329 [https://doi.org/10.1183/13993003.02329-2018]. 


\section{References}

1 Beasley R, Bird G, Harper J, et al. The further paradoxes of asthma management: time for a new approach across the spectrum of asthma severity. Eur Respir J 2018; 52: 1800694.

2 Global Initiative for Asthma. Global strategy for asthma management and prevention. 2018. www.ginasthma.org Anonymous. Using beta2 stimulants in asthma. Drug Ther Bull 1997; 35: 1-4.

$4 \quad$ Nannini LJ. Overreliance link between asthmatic subjects and short-acting $\beta 2$ agonists. Pulm Pharm Ther 2018; 50: 80-81.

5 Nannini LJ, Neumayer NS. Treatment step 1 for asthma should not be left blank, and SABA-only might not be a treatment step 1 option for asthma. Respiration 2018; 95: 212-214.

6 Pauwels RA, Pedersen S, Busse WW, et al. Early intervention with budesonide in mild persistent asthma: a randomised, double-blind trial. Lancet 2003; 361: 1071-1076.

7 Frey U, Brodbeck T, Majumdar A, et al. Risk of severe asthma episodes predicted from fluctuation analysis of airway function. Nature 2005; 438: 667-670.

8 Rodrigo GJ, Plaza Moral V, Bardagí Forns S, et al. Guía ALERTA 2. América Latina y España: Recomendaciones para la prevención y el Tratamiento de la exacerbación Asmática [ALERTA 2 guidelines. Latin America and Spain: recommendations for the prevention and treatment of asmatic exacerbations]. Arch Bronconeumol 2010; 46: Suppl. 7, 2-20.

9 Rodrigo GJ, Neffen H, Colodenco FD, et al. Formoterol for acute asthma in the emergency department: a systematic review with meta-analysis. Ann Allergy Asthma Immunol 2010; 104: 247-252.

10 Kerstjens HA, Engel M, Dahl R, et al. Tiotropium in asthma poorly controlled with standard combination therapy. N Engl J Med 2012; 367: 1198-1207.

11 Kew KM, Karner C, Mindus SM, et al. Combination formoterol and budesonide as maintenance and reliever therapy versus combination inhaler maintenance for chronic asthma in adults and children. Cochrane Database Syst Rev 2013; 12: CD009019.

Copyright @ERS 2019

From the authors:

We appreciated the letter from L.J. Nannini, which further highlights the paradoxes of short-acting $\beta_{2}$-agonist (SABA) treatment in asthma, the requirement for guidelines to be revised in accordance with available evidence, and the proof of concept initiative to eliminate SABA therapy altogether in their asthma department.

The proposition of replacement of SABA use with inhaled corticosteroid (ICS)/fast-onset $\beta$-agonist use in the emergency room (ER) or inpatient setting, as well as for self-administration in the community, is raised. This treatment approach is supported by the evidence that repeat doses of ICS in the setting of acute severe asthma in the ER markedly reduces the risk of hospital admission (odds ratio 0.44, 95\% CI 0.31-0.62) [1]. Furthermore, in patients treated with systemic steroids, repeat doses of ICS also reduce the risk of hospital admission (odds ratio $0.54,95 \%$ CI $0.36-0.81$ ).

Based on this evidence, it is likely that the administration of repeat doses of ICS delivered as a combination ICS/fast-onset $\beta$-agonist would have greater efficacy than repeat doses of SABA when administered for acute severe asthma in both the ER and community setting, both with and without concomitant systemic steroid use. This would be consistent with studies which have shown that the self-administration of ICS/formoterol as a reliever therapy, either with [2,3] or without [4] maintenance ICS/long-acting $\beta_{2}$-agonist (LABA) therapy, markedly reduces the risk of severe exacerbations compared with SABA reliever therapy. This approach encompasses the treatment concept of "rescue" as well as "reliever" therapy.

L.J. Nannini also raises the important issue that a distinct terminology is required to define the ICS/ fast-onset $\beta$-agonist reliever therapy regimen, and proposes the term "anti-inflammatory reliever therapy". The term anti-inflammatory reliever therapy would apply to both ICS/SABA and ICS/fast-onset LABA reliever therapy, either alone or together with maintenance therapy, and represent both "reliever" and "rescue" use, either self-administered by patients in the community or administered by health professionals in the setting of a severe exacerbation. The term may help focus the attention of the prescriber to the desirable attributes of this treatment, namely relief of symptoms and suppression of airways inflammation

@ERSpublications

We support the proposal that anti-inflammatory reliever therapy replaces the current use of short-acting $\boldsymbol{\beta}_{2}$-agonist reliever therapy in adults across the range of asthma severity http://ow.ly/uUtP30nHqhj

Cite this article as: Beasley R, Bird G, Harper J, et al. Asthma paradoxes: time for a new approach across the spectrum of asthma severity. Eur Respir J 2019; 53: 1900218 [https://doi.org/10.1183/13993003.00218 2019]. 
with the resulting reduction in severe exacerbation risk. We support the use of this terminology, with the aim of anti-inflammatory reliever therapy replacing the current use of SABA reliever therapy across the range of asthma severity.

Richard Beasley $\oplus^{1,2,3}$, Grace Bird $\oplus^{1}$, James Harper $\oplus^{1}$ and Mark Weatherall $\oplus^{3,4}$

${ }^{1}$ Medical Research Institute of New Zealand, Wellington, New Zealand. ${ }^{2}$ Victoria University of Wellington, Wellington, New Zealand. ${ }^{3}$ Capital and Coast District Health Board, Wellington, New Zealand. ${ }^{4}$ University of Otago, Wellington, New Zealand.

Correspondence: Richard Beasley, Medical Research Institute of New Zealand, Private Bag 7902, Wellington 6242, New Zealand. E-mail: richard.beasley@mrinz.ac.nz

Received: Jan 302019 | Accepted: Jan 312019

Conflict of interest: R Beasley reports grants and personal fees from the Health Research Council of NZ, grants and personal fees from AstraZeneca, grants and personal fees from GlaxoSmithKline, and grants from Genentech, outside the submitted work. G. Bird has nothing to disclose. J. Harper has nothing to disclose. M. Weatherall has nothing to disclose.

\section{References}

1 Edmonds ML, Milan SJ, Camargo CA Jr, et al. Early use of inhaled corticosteroids in the emergency department treatment of acute asthma. Cochrane Database Syst Rev 2012; 12: CD002308.

2 Patel M, Pilcher J, Pritchard A, et al. Efficacy and safety of maintenance and reliever combination budesonide-formoterol inhaler in patients with asthma at risk of severe exacerbations: a randomised controlled trial. Lancet Respir Med 2013; 1: 32-42.

3 Sobieraj DM, Weeda ER, Nguyen E, et al. Association of inhaled corticosteroids and long-acting beta-agonists as controller and quick relief therapy with exacerbations and symptom control in persistent asthma: a systematic review and meta-analysis. JAMA 2018; 319: 1485-1496.

4 O'Byrne P, FitzGerald M, Bateman ED, et al. Efficacy and safety of as-needed budesonide/formoterol in mild asthma. N Engl J Med 2018; 378: 1865-1876. 